\title{
Research and Practice of the Open Experimental Teaching Mode In the University
}

\author{
Qiang Song ${ }^{1, a^{*}}$ and Ling Xia Liü,b \\ ${ }^{1}$ Computer School, Anyang Institute of Technology, Anyang City,455000, China \\ ${ }^{2}$ Software School, Anyang Normal University, Anyang City,455000, China \\ aysq168@163.com, 'Ilx@aynu.edu.cn
}

\begin{abstract}
Keywords: Open experimental teaching; Open management mode; Connotations construction Laboratory construction; Talent cultivation
\end{abstract}

\begin{abstract}
Combining with the innovation practices of experimental teaching within recent years, this paper puts forword the connotations and characteristics of the open experimental teaching mode, that is, the diversification and openess of experimental teaching goals, subject, teaching mode, teaching content and teaching resource. It indicated that the open experimental teaching can not only improve the experimental skills and abilities of students, but also has a great significance at the cultication of their innocative awareness and researching abilities. It puts forward the modularity of experiment courses and the layering of experiment items are main connotations of the open experimental teaching mode. Opening experimental teaching mode can hasten the connotations construction of open experiments and change the study method in some extent.
\end{abstract}

\section{Introduction}

In recent years, driven by the evaluation of undergraduate teaching level around the training objectives, the enhance of practical ability and the innovative spirit, the university gradually increase investment in the construction of the laboratory, experimental teaching equipment have a more big update, experimental teaching environment has an significant improvement; the understanding to experimental teaching function has substantially improved, the status and importance of the experimental teaching are increasingly prominent; laboratory construction and experimental teaching reform have been significant progress.

In this context, the laboratory construction and experimental teaching reform have been gradually from focusing on laboratory hardware and environment construction, focusing on the experimental teaching content and teaching method reform, to build with ability training as the core of modularization and hierarchy of the experimental teaching system, to adapt to the laboratory opening experimental teaching mode and open experimental teaching management mode, to transfer to the experiment teaching quality evaluation system with ability training of personalized and diversified developing, and to move to the network experimental teaching resources and management platform construction aspects, a lot of researches and practices are carried out, many research results and practical experience has obtained which can be made use of [1-13]. The deep reform of experimental teaching aims to enhance the connotation construction of the open laboratory, to play special function of experimental teaching, to improve the quality of experiment teaching, and promote the comprehensive development of students' knowledge, ability and quality.

\section{The Connotation Features Of Opening Experimental Teaching Mode}

The connotation features of the open experiment teaching mode is the openness of the experimental teaching, namely: the goal of experimental teaching is open, the subject of the experimental teaching is open, the way of experimental teaching is open, the contents of experiment teaching is open, and the resource of experiment teaching is open. The features of openness is based on the complexity of 
experimental teaching process and ability training process, the diversity of training mode and teaching methods, the diversity of the individuality of the talent and development goals, and other factors. The connotation and features of opening experimental teaching mode is as follows.

Restore The Irreplaceable Special Role Of Experimental Teaching. The characteristics of applied talents is good at applying science and technology to the actual, good at transforming scientific research achievements into productivity. Applied talent's training quality, therefore, in a large extent is reflected in the ability to integrate theory with practice, practice ability, and innovation ability.

Experimental teaching has a special function to improve students' comprehensive quality, cultivate students' innovation spirit and practice ability[1]. The fundamental purpose of the experiment is to study the methods of experimental measurement, the scientific thinking and the basic research of disciplines, this is the most basic, and the validation should be on a relatively minor position [2]. Experimental process to a certain extent, is a kind of scientific inquiry process or reproduce the experimental process of scientific inquiry, which increases the training opportunities of intuition thinking and creative thinking. The function of the experiment teaching is not only master the methods of scientific experiments, skills, and verifying the scientific principle, reproducing the natural phenomenon, the more important function is the discovery and exploration of the unknown.

Open experimental teaching mode provides this exploratory, autonomous learning and teaching environment. Students use knowledge to choose or bring forward experiment project, design the experiment scheme, organize experimental instrument, install and debug, troubleshoot, observe the phenomena, analyze data, and come to a decision. Therefore, open experimental teaching mode restores the irreplaceable role in experiment teaching.

Among them, the student is the subject of the experiment, the process of the students participate the experiments can be expressed in the following flow chart.

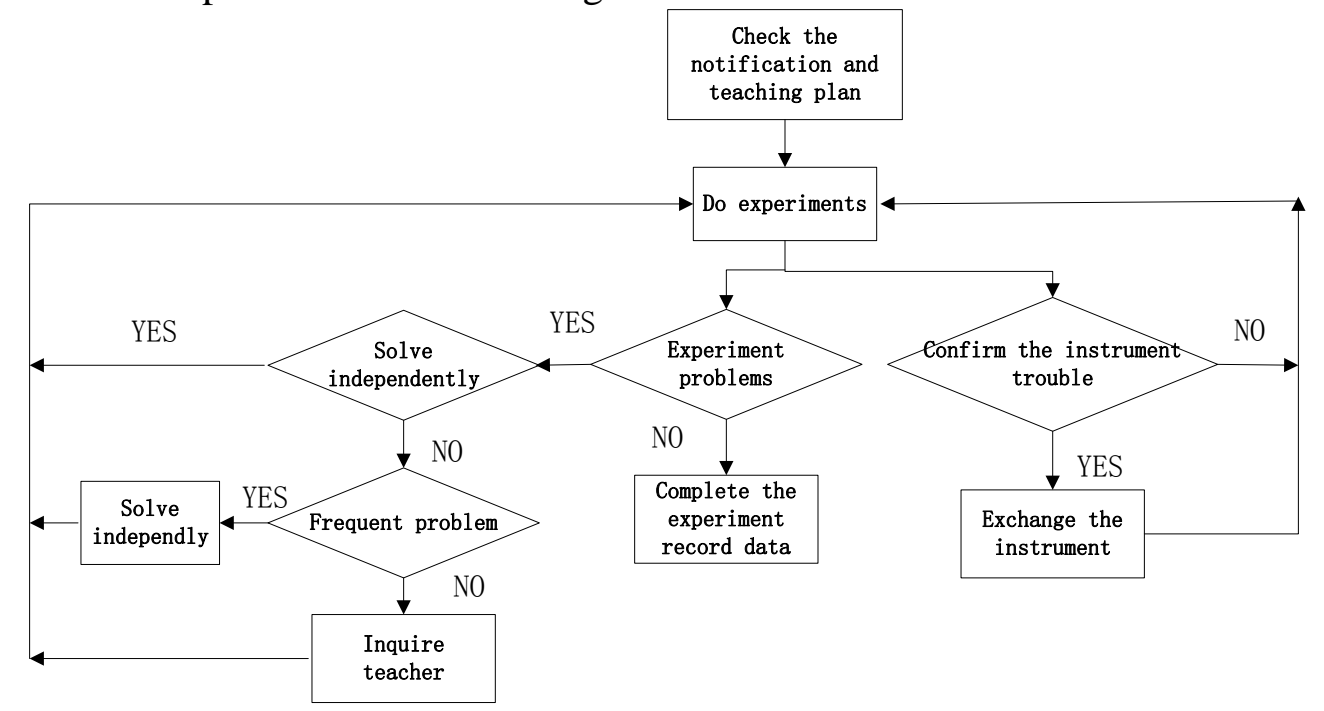

Fig. 1 Experiment flow chart for students

Reflect Student's Subject Status And Teacher's Leading Role. The characteristics of the open experiment teaching mode is the student's autonomous learning, the teachers become the knowledge learning and ability training designers, organizers and directors for students, which reflects student's subject status and teacher's leading role. In the open experiment teaching process, students have greater independence, autonomy, exploratory, which can fully reflect the students is the subject. On the one hand, the experimental operation, data measurement, qualitative analysis, quantitative calculation, and getting the conclusion require students to independently complete. Students in the experimental teaching process become worthy subject, a change is from the closed bound state to the open free state, which increases the freedom of students' study, stimulates students' learning enthusiasm, greatly promotes the students' autonomous learning, and makes students become the subject of experiment teaching. On the other hand, under the open experimental teaching mode, 
students according to their own intelligence, ability, interest and ambition, choose their own learning content and learning style.

Teachers play domination role in the experimental teaching, the teacher's daily work can make a summary in the diagram below.

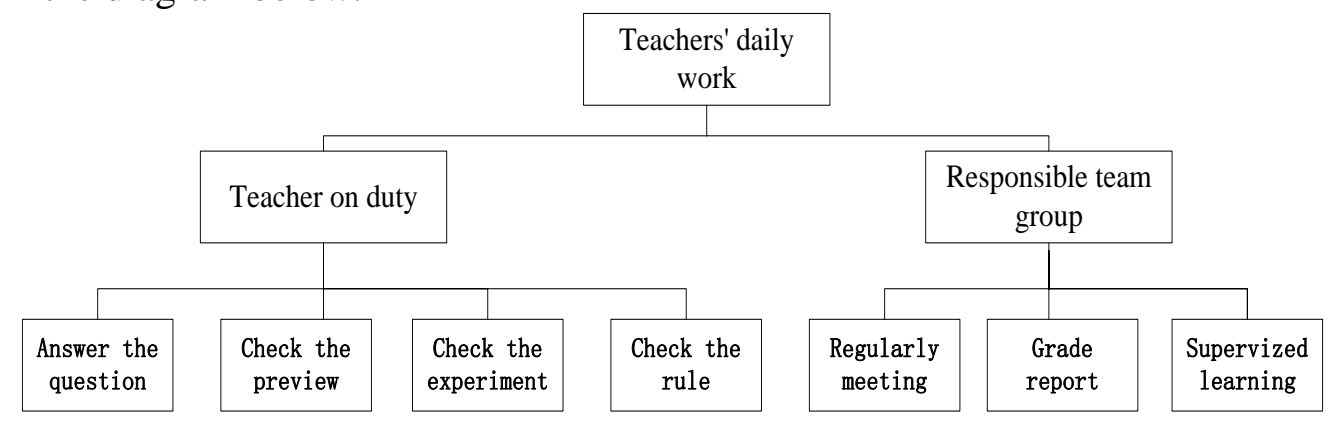

Fig. 2 Teacher's daily work

The Experimental Course System With Modular And Hierarchical Connotation. With the implementation of the higher education facing the 21st century teaching contents and curriculum system reform plan, the experimental teaching course system, teaching content has been gradually transforming to multi-level and modular curriculum structure. This experiment teaching content becomes a course, the experiment project becomes hierarchical, course becomes modular, which are the main connotation of open experimental teaching mode. Building the multi-level and modular experimental curriculum system in order to enhance students' practice ability and innovation consciousness, innovation spirit and innovation ability, promote the comprehensive development of students' knowledge, ability and quality as the goal, and in the framework of curriculum group of knowledge system, becomes the carrier of gradually realize the special function of experiment teaching.

In this kind of multi-level and modular experimental curriculum system, because the inner link of the curriculum group of knowledge system and the intersection and infiltration among disciplines, the experiment design, experiment method, and experiment skill reflects the characteristics with generality and comprehensiveness. This kind of curriculum system will help to achieve the special function of experimental teaching, and make the experimental teaching goal clearer.

Reflects The Hierarchy And The Comprehensive Of Ability Training. The talent cultivation process of practical ability and innovation ability is complicated, cultivating pattern is varied. This is due to the development of talented person's intelligence, ability, interest, and specialty has the complexity and diversity. Talent individuals have the development potential in one or several aspects, good education teaching mode is the mode to sufficiently promote the development of students.

People's practice ability and innovation ability have layers (the ability to integrate theory with practice, the integrated use of knowledge and skills, problem solving skills, innovative ability, etc.).Therefore, the cultivation of practice ability also has layers. Experiment teaching content itself has a multi-level and comprehensive, that is the experiment project hierarchical, modular curriculum. Therefore, ability training level and comprehensive are conceived in this curriculum system in the teaching process, which is obtained through basic, comprehensive, designing, researching experiment and course design, graduation design, subject contests, etc. As a result, the open experiment teaching mode embodies the hierarchy and the comprehensive of ability training.

Open Laboratory Is The Main Form Of Open Experiment Teaching. Opening laboratory has become the basic requirements of experimental teaching reform and modern laboratory management. The connotation and form of open laboratory is diverse, not only it refers to the open time and space, more important it refers to the teaching content, teaching methods and teaching means, it is the open teaching concept. Therefore, the open laboratory is not only the open management pattern, especially the open teaching mode, which is the basis and the main form of the implementation of open experiment teaching mode. In opening experimental environment, students can select experiment contents according to their abilities, professional characteristics, interests and learning style, through 
active participation, autonomous learning, free inquiry of students, they can experience the happy experiment, which reflects the education teaching idea based on students' development, education humanization and personalized learning; Opening laboratory is the foundation of autonomous learning mode, it is helpful to arouse the students' learning initiative and enthusiasm to play learning potential, and conducive to the development of personalized and talent cultivation of students' autonomous learning ability.

Opening laboratory has a variety of ways, including curriculum design, graduation design, structure design competition of college students, electronic design competition, mathematical modeling contest, mechanical innovation design competition, and so on, the subjects competition is such as "innovation credits" second classroom activity, these are the opening laboratory modes and routes.

The Network Experimental Teaching Platform Is The Foundation Of The Opening Experimental Teaching. With the wide use of computer network technology and database technology, the experimental teaching management platform based on campus network, information platform and the establishment of experimental teaching resource provides the necessary foundation for the improvement of teaching methods and teaching means, forming the open experiment teaching mode, on the deeper layer to promote the experimental teaching reform, and provides experimental teaching with deeper and broader space for development.

Facing to the uncertain problems such as teaching object, contents, and time factors and so on, brought by the opening experimental teaching, the network experimental teaching platform has become the basis of open experimental teaching.

Below in figure 3 an open network experimental teaching system structure is given, the people who accesses to the experiment system must first accept authentication, different identity needs launch from different landing interface, visitors with different identities who are authorized permissions are not the same.

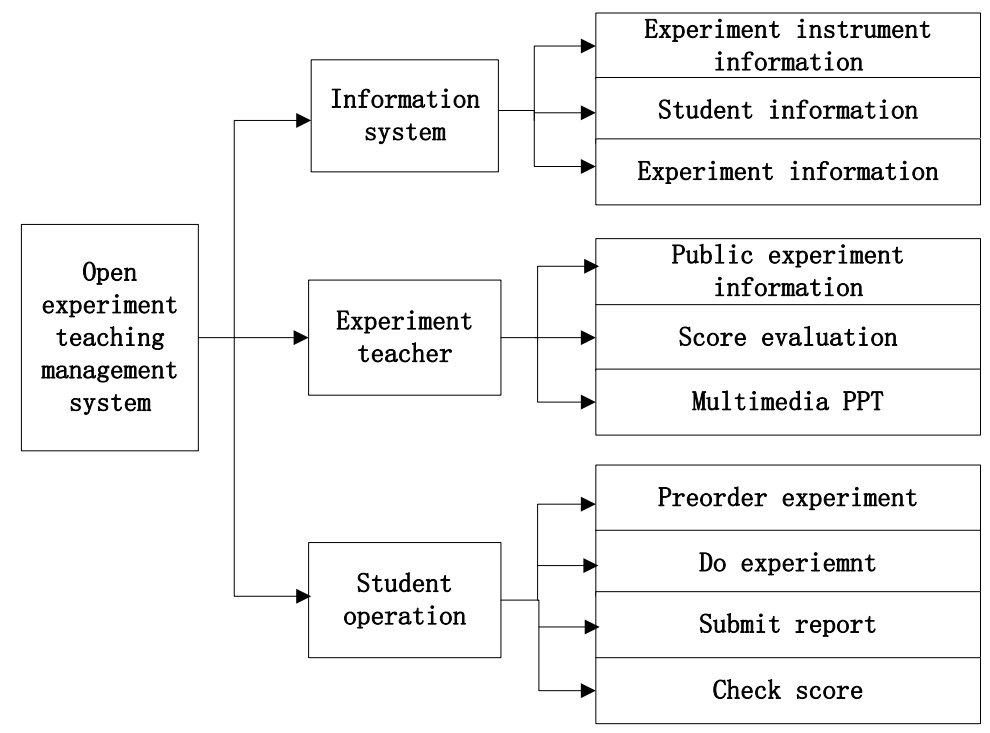

Fig. 3 Experiment teaching network system

Network experimental teaching platform not only optimizes the management process and improve the efficiency of management, also provides diversified learning style, makes it possible to students' autonomous learning, further improves the laboratory opening degree. At the same time, the open experimental teaching mode makes the process of interaction between teachers and students extends outside of the classroom, the leading role of teachers plays in greater degree.

\section{Conclusion}

Based on applied talents training goal of practical features, the complexity of practical ability training process and the diversity of education mode, etc., combined with recent years experimental teaching reform practice, this paper puts forward the connotation and characteristics of the open experiment 
teaching mode, namely, the goal, subjects, methods, contents, resources and others of diversified and open experimental teaching, which points out the function of experimental teaching is to cultivate the student's spirit good at practice and innovation, the open experiment teaching mode restores the special function of experimental teaching. The experimental curriculum modular and project layering is put forward is the main connotation of open experimental teaching mode. The open experiment teaching mode embodies the structure and the comprehensive of ability training, which presents the principle of personalized teaching to teach students according to their aptitude, follow the cognitive law of talent development. Opening laboratory is the foundation and the main form of the implementation of open experiment teaching mode; the network experimental teaching platform is the foundation of the opening experimental teaching. Open experimental teaching mode promotes the connotation construction of open laboratory and to some extent changes the personnel training mode and students' learning styles.

\section{Reference}

[1] G.H. Wu, T. Yang, and X.W. Zhao: The training system construction of undergraduate's innovative spirit and practice ability, Journal of higher engineering education research. 3(2002) 21-23.

[2] Z.Y. Zheng, H. Gao, and Z.L. Zhang, The physical experiment teaching mode innovation practice and discussion, Journal of laboratory science. 4(2008) 30-32.

[3] Y.H. Zhang, L. Yang. Research and practice of opening experimental teaching of Electronic technology, Journal of laboratory science. 4(2008) 25-27.

[4] Y.L. Chen, The exploration and practice of innovative experimental teaching model, Journal of Heilongjiang province higher education research. 1(2005)154-155.

[5] M.S. Shen, Z.L. Zhuang, and M. Chen, Biology experimental teaching system reform and practice for undergraduates, Journal of China university teaching. 3(2006) 12-13.

[6] S.K. Zhu, Exploration and practice of open experiment teaching model, Journal of physics experiment. 6(2007) 86-89.

[7] X.H. Liu, J.S. Yang, and C.P. Zhu, Research and practice of teaching model to cultivate undergraduate physics experiment "four abilities", Journal of experimental technology and management. 12(2008) 154-156.

[8] L.C. Wu, H.Y. Zhao, and B. Yang, The construction and study of multi-level experiment teaching mode, Journal of Shenyang normal university. 4(2008) 509-512.

[9]Y.J. Yu, H.G. W, and J.G. Hao, The study of open experiment teaching mode and management system, Journal of eastern Shandong University. 3(2008) 241-244.

[10] Z.W. Wang, T.M. Zhang, Build a multi-level modular open experimental teaching system. Journal of Heilongjiang province higher education research. 5(2008) 162-163.

[11] G.Q. Gai, G.L. Song, The research and practice of open experiment teaching management mode, Journal of Heilongjiang province higher education research. 5(2009) 162-164.

[12] R.J. Hu, Build an open experimental teaching environment, develop independent open experimental teaching, Journal of laboratory research and exploration. 7(2006) 822-826.

[13] Y.H. Zhang, L. Yang. Research and practice of opening experimental teaching of Electronic technology, Journal of laboratory science. 4(2008) 25-27. 